\title{
Supply Chain Cooperative Advertising and Ordering Model for the Loss Averse Retailer
}

\author{
Lei Jiang* \\ Department of Mathematics, Chengdu Textile College, Chengdu, China. \\ * Corresponding author. Tel.: (+8628)87840059; email: roraldo9@163.com \\ Manuscript submitted December 20, 2017; accepted March 2, 2018. \\ doi: 10.17706/ijapm.2018.8.3.31-44
}

\begin{abstract}
The loss averse retailer sells the newsboy type of product to the consumers in a one-period two-echelon supply chain, where the risk neutral manufacturer supply the product to the retailer. When the market demand only depend on the retailer's advertising investment and is uncertain, this paper discusses the manufacturer's participation rate ,the retailer's advertising expenditures and order quantity decision problems in a Stackelberg game. After characterizing the equilibrium solution of this game, this paper show the effect of each parameter on optimal decisions. The results reveal that the loss averse retailer's optimal order quantity is less than the risk neutral retailer's optimal decision and decrease as the loss aversion level increases. Maybe it's the reason that the upstream manufacturer will share the advertising investment of the downstream retailer, the retailer's optimal local advertising expenditure is yet greater than the risk neutral retailer's optimal decision and is increasing in the loss aversion level. When the degree of loss aversion become larger ,the manufacturer's optimal participation rate first increases and then decreases until zero. The numerical example is given to analyze the effects of parameter on some optimal decisions and also confirm the relevant conclusion.
\end{abstract}

Key words: Cooperative advertising, loss aversion, stackelberg game, demand uncertainty, supply chain management.

\section{Introduction}

In the supply chain management problem, companies will cooperate in order to achieve maximum profits as much as possible. Cooperative advertising is a very important means, at the same time, the two parties will play a game. The review by Aust and Buscher [1] introduce many information regarding the models and knowledge on cooperative advertising .

With the increasing of uncertainty factors affecting the market demand, the market demand of the product is often uncertain. There has been many research [2], [3] on the supply chain cooperative advertising focused on that market demand is uncertain.These studies are almost focused on risk neutrality (i.e., decision makers are completely rational) in decision maker's risk attitudes. However, in real life, people often have the behavior characteristics of loss aversion [4]. This article is distinguished from other research in that we assume that one of the decision makers is a loss averse retailer, in which case the further expansion of the cooperative advertising and game study under demand uncertainty. In this paper, we discuss the two-echelon supply chains with loss averse retailer and co-operative advertising. Huang and Li [5] has discussed three vertical co-op advertising models in which based on two non-cooperative games and 
one cooperative game. Li and Huang [6] develop three strategic models for determining equilibrium marketing and investment effort levels for a manufacturer and a retailer in a two-member supply chain. They examine the effect of supply chain on the di8erences in profits resulting from following coordinated strategies as opposed to leader-follower strategies. Based on Li and Huang, Xie and Ai [7] extend the results in the manufacturer-dominated game, they reveal that the manufacturer always prefers the leader-follower structure rather than the simultaneous move structure, and the retailer always prefers the simultaneous move structure rather than the leader-follower structure. Different from the above situation that the market demand is determined, Chen [8] investigates the problem of determining the optimal order quantity, the local advertising level, and the investment in promoting national brand name recognition of a short-life cycle commodity within a manufacturer-retailer supply chain under demand uncertainty.

On the other hand, the correlation studies involves loss aversion. Maurice E. Schweitzer [9] first incorporate loss aversion into the newsvendor problem, they show that the loss averse newsvendor will reduce the order quantity if there is no shortage cost, compared to the risk neutral newsvendor. However, on the basis of this conclusion, Wang and Webster[10] demonstrate that a loss averse newsvendor may order more than a risk neutral newsvendor if shortage cost is not negligible, they also find that the loss averse newsvendor's optimal order quantity decrease in retail price and increase in wholesale price. Lee and Li et al. [11] show how the newsvendor's loss aversion behaviour affects his ordering decision. Luo and Chen [12] investigate the coordination of a supply chain consisting of a loss averse supplier and a risk neutral buyer, under shortage-penalty-surplus-subsidy (SPSS) contracts, they obtain the supplier and the buyer's optimal strategy. There is a distinct difference that the supply chain related to option contracts between the paper [12] and the other literature. Charles X. Wang [13] considers a decentralized supply chain, in which the manufacturer is risk neutral and the retailer is loss averse, their results lend insight into how a manufacturer can design a contract to improve total supply chain, manufacturer, and retailer performance, moreover, they show that there exists a special class of distribution-free GLB contracts that can coordinate the supply chain. Their mainly research is how to coordinate the supply chain if the retailer is loss averse. But, they did not investigate and describe the optimal decision of the manufacturer and the retailer.

Different from above researches about co-operative advertising and risk control in single period newsvendor problem, and to the best of our knowledge, the research of co-operative advertising combining loss aversion under demand uncertainty is few. So, in order to fill in the gaps, we conduct this research. The main purpose of this paper is to study the effect of loss aversion degree on the optimal decision of manufacturer and retailer in the case of uncertain demand if retailer is loss averse, moreover, the optimal decisions is compared with that retailer is risk neutral. The main contributions and innovations of this paper are as follows: (i) Different from the traditional supply chain model, in the case of the retailer's risk attitude is loss averse, the loss aversion coefficient is introduced, and the cooperative advertising model of the supply chain is established, On the basis of this, we describe the equilibrium solution of the model. (ii) The manufacturer and the retailer carry out Stackelberg game, We analyze the conclusion in the case of cooperative advertising by theoretical method and numerical example, the optimal decision of the upstream and downstream enterprises with the trend of the loss averse level of the retailer, and provide theoretical support for enterprises to carry out cooperative advertising.

The remainder of this paper is organized as follows: The assumptions and the discussion of the cooperative advertising basic model of supply chain is presented in Section 2; In Section 3, we formulate the model in Stackelberg game and describe the equilibrium results; Some sensitivity analysis are fulfilled in Section 4; Section 5 provides a numerical study to investigate the equilibrium solutions with some parameter variation; Section 6 summarizes the findings from the research and suggests future research 
directions.

\section{Assumptions and the Model}

We consider the supply chain with one manufacturer and one retailer. Facing the market consumers, the retailer sells the newsboy type of product (i.e., short life-cycle products) and the manufacturer is the supplier. The retailer primarily order the product (the order quantity is $q$ ) from the manufacturer at the constant unit wholesale price $w$, and sells the product to consumers at the unit retail price $p$ during the selling season. The product's constant unit manufacturing cost is c. For simplify this problem, the retailer's sales cost, the manufacturer's shortage cost , the retailer's shortage penalty cost and the salvage of unsold products are not considered in this paper ([9], [11]). To stimulate the market demand, the manufacturer and the retailer carry out cooperative advertising. As the special case, we assume that the advertising investment in the market is only done by the retailer. The retailer's local advertising expenditure is a and the manufacturer's national advertising expenditure is zero [14]. In order to increase the market demand and stimulate the retailer's investment, the manufacturer give the retailer some subsidies of local advertising expenditure by the variable $t$ and denote the manufacturer participation rate (i.e. the percentage that the manufacturer agrees to pay the retailer to subsidize the local advertising cost). The endogenous variables are $\mathrm{t}, \mathrm{q}$ and $\mathrm{a}$; the other variables are exogenous. Without loss of generality and in order to avoid any trivial case, we assume $0<c<w<p$ in this paper.

During a single selling season, the market demand is only the local advertising investment-dependent and is stochastic. In this paper, we capture the randomness in the market demand by the additive form. The additive demand uncertainty is widely used in the literature [15]-[18 ]. We thus model the demand for the product at the retailer, denoted by $\mathrm{D}(\mathrm{a}, \varepsilon)$, as:

$$
D(a, \varepsilon)=d(a)+\varepsilon
$$

where $d(a)>0$ is the expected demand of the market product, which is determined by the retailer's local advertising investment. Moreover, $\mathrm{d}(\mathrm{a})$ is an increasing and concave function with respect to a and is continuous. For convenience and simplify the problem behind in this paper, we assume that the third derivative of $d(a)$ is positive, i.e., $d^{\prime}$ ' $^{\prime}(a)>0$. (Notes: we review the demand function related to cooperative advertising and game, we find that the most literatures either adopt a square root function ([19]-[24]) or a power function ([5], [19], [25], [26]) to describe the form of the market demand related to advertising expenditures, while only few literature [27], [28] use the linear demand function. So, we do not consider the linear demand, after computing the third order derivative of the other demand function(i.e., the square root function and the power function)with respect to advertising expenditures, we give the assumptions above). $\varepsilon$ is a random variable(noise) with probability density function(PDF) $f(x)$ and cumulative distribution function $(C D F) F(x)$ that have support $[A, B]$, where $B>A$ and expectation $\mathrm{E}(\varepsilon)=0 . \quad \overline{\mathrm{F}}(\mathrm{x})=1-\mathrm{F}(\mathrm{x})$ is denoted the tail distribution.

Similar to the loss aversion utility function of the literature [8]-[10] , we still consider that the retailer's utility function is piecewise-linear, as:

$$
U(X)= \begin{cases}X-X_{0}, & X \geq X_{0} \\ \lambda\left(X-X_{0}\right), & X<X_{0}\end{cases}
$$

where $\lambda$ is the retailer's loss aversion coefficient. We assume $\lambda \geq 1$, which means that people are more sensitive losses than to same sized gains. The retailer is risk neutral when $\lambda=1$ and if $\lambda>1$,then the retailer is risk averse. Higher value of $\lambda$ corresponds to the higher level of retailer's loss aversion. There is a kink at the reference level $\mathrm{W}_{0}$, Without loss of generality, we normalize the newsvendor's reference level to zero(i.e., $\left.\mathrm{W}_{0}=0\right)$ ([10], [12], [13]). 
The profit functions of the manufacturer and the retailer can be indicated as follows based on these assumptions, respectively:

$$
\begin{gathered}
\pi_{M}=(w-c) q-t a \\
\pi_{\mathrm{R}}= \begin{cases}p D(a, \varepsilon)-(1-t) a-w q, & D(a, \varepsilon) \leq q \\
p q-(1-t) a-w q, & D(a, \varepsilon)>q\end{cases}
\end{gathered}
$$

where $q \geq 0, a \geq 0,0 \leq t \leq 1$

Remark. Throughout this paper, the subscript "M" and "R" means the parameters corresponding to the manufacturer and the retailer, respectively .

\section{Stackelberg Game}

The same as our findings, we continue model the relationship between the manufacturer and the retailer as a sequential non-cooperative game, the retailer is the leader and the manufacturer is the follower. We have analyzed and proved the following conclusions:

Theorem1. $\mathrm{E}\left(\mathrm{U}\left(\pi_{\mathrm{R}}\right)\right)$ is concave for all $\mathrm{q}$ and $\mathrm{a}(A \leq q-d(a) \leq B)$, moreover , there exists the unique optimal nonnegative value $\left(\mathrm{q}^{*}, \mathrm{a}^{*}\right)$ that maximizes the retailer's expected utility and satisfies the following first-order conditions:

$$
\begin{gathered}
(p-w)-p F\left(q^{*}-d\left(a^{*}\right)\right)-w(\lambda-1) F\left(q_{1}\left(q^{*}, a^{*}\right)-d\left(a^{*}\right)\right)=0 \\
p d^{\prime}\left(a^{*}\right) F\left(q^{*}-d\left(a^{*}\right)\right)+(\lambda-1)\left[p d^{\prime}\left(a^{*}\right)-(1-t)\right] F\left(q_{1}\left(q^{*}, a^{*}\right)-d\left(a^{*}\right)\right)-(1-t)=0
\end{gathered}
$$

Theorem 2. If $\mathrm{t}^{*}$ is the optimal decision of the manufacturer, then it satisfies the first-order condition:

$$
(w-c) \frac{M\left(t^{*}\right)}{K\left(t^{*}\right)}-a\left(t^{*}\right)+\frac{1}{p-w} \frac{t^{*}}{d^{\prime \prime}\left(a\left(t^{*}\right)\right)}=0
$$

where

$$
\begin{gathered}
M(t)=w(p-w)(\lambda-1) d^{\prime \prime}(a(t)) a(t) I_{2}(t)-d^{\prime}(a(t))\left[p^{2} I_{1}(t)+w^{2}(\lambda-1) I_{2}(t)\right] ; \\
K(t)=(p-w) d^{\prime \prime}(a(t))\left[p^{2} I_{1}(t)+w^{2}(\lambda-1) I_{2}(t)\right] ; \\
I_{1}(t)=f(q(t)-d(a(t))) ; I_{2}(t)=f\left(q_{1}(q(t), a(t))-d(a(t))\right) .
\end{gathered}
$$

By theorem 2,we find that only the first order condition of the manufacturer's optimal solution is given. In order to get more insight, based on the theorem 2, We can get,

Theorem 3. If $q=q(t), a=a(t)$ satisfy the equation (8) and (9), when

$w<(p-w)(w-c)$ and $0 \leq t^{*} \leq 1$ is the optimal decision of the manufacturer, $\left(\mathrm{t}^{*}, \mathrm{q}\left(\mathrm{t}^{*}\right), \mathrm{a}\left(\mathrm{t}^{*}\right)\right)$ is the unique Stackelberg equilibrium.

\section{Proof of Theorem 3}

According to theorem 2, we know

$$
\frac{d E\left(\pi_{M}\right)}{d t}=(w-c) \frac{d q^{*}}{d t}-a(t)-t \frac{d a^{*}}{d t} . \quad \text { Since } \frac{d q^{*}}{d t}=\frac{M(t)}{K(t)}, \frac{d a^{*}}{d t}=-\frac{1}{p-w} \frac{1}{d^{\prime \prime}(a(t))}
$$

we let $X(t)=\frac{d E\left(\pi_{M}\right)}{d t}=(w-c) \frac{M(t)}{K(t)}-a(t)+\frac{t}{p-w} \frac{1}{d^{\prime \prime}(a(t))}$

$$
\forall 0 \leq \mathrm{t}_{1}<\mathrm{t}_{2} \leq 1, \mathrm{X}\left(\mathrm{t}_{1}\right)=(\mathrm{w}-\mathrm{c}) \frac{\mathrm{M}\left(\mathrm{t}_{1}\right)}{\mathrm{K}\left(\mathrm{t}_{1}\right)}-\mathrm{a}\left(\mathrm{t}_{1}\right)+\frac{\mathrm{t}_{1}}{\mathrm{p}-\mathrm{w}} \frac{1}{\mathrm{~d}^{\prime \prime}\left(\mathrm{a}\left(\mathrm{t}_{1}\right)\right)}
$$




$$
\begin{gathered}
X\left(t_{2}\right)=(w-c) \frac{M\left(t_{2}\right)}{K\left(t_{2}\right)}-a\left(t_{2}\right)+\frac{t_{2}}{p-w} \frac{1}{d^{\prime \prime}\left(a\left(t_{2}\right)\right)} \text {, then } X\left(t_{1}\right)-X\left(t_{2}\right)=(w-c)\left[\frac{M\left(t_{1}\right)}{K\left(t_{1}\right)}-\frac{M\left(t_{2}\right)}{K\left(t_{2}\right)}\right]+a\left(t_{2}\right)-a\left(t_{1}\right)+ \\
\frac{1}{p-w}\left[\frac{t_{1}}{d^{\prime \prime}\left(a\left(t_{1}\right)\right)}-\frac{t_{2}}{d^{\prime \prime}\left(a\left(t_{2}\right)\right)}\right] .
\end{gathered}
$$

Note $Y_{1}=(w-c)\left[\frac{M\left(t_{1}\right)}{K\left(t_{1}\right)}-\frac{M\left(t_{2}\right)}{K\left(t_{2}\right)}\right]+a\left(t_{2}\right)-a\left(t_{1}\right) ; Y_{2}=\frac{1}{p-w}\left[\frac{t_{1}}{d^{\prime \prime}\left(a\left(t_{1}\right)\right)}-\frac{t_{2}}{d^{\prime \prime}\left(a\left(t_{2}\right)\right)}\right]$

For $\mathrm{Y}_{2}$, we let $\theta(\mathrm{t})=\frac{\mathrm{t}}{\mathrm{d}^{\prime}{ }^{\prime}(\mathrm{a}(\mathrm{t}))}$ and take the first derivative of $\theta(\mathrm{t})$ with respect to $\mathrm{t}$,

$\theta^{\prime}(\mathrm{t})=\frac{\mathrm{d}^{\prime \prime}(\mathrm{a}(\mathrm{t}))-\mathrm{td}^{\prime \prime \prime}(\mathrm{a}(\mathrm{t})) \frac{\mathrm{da}^{*}}{\mathrm{dt}}}{\left(\mathrm{d}^{\prime \prime}(\mathrm{a}(\mathrm{t}))\right)^{2}}<0, \theta(t)$ is decreasing in $t$, we get: $\frac{\mathrm{t}_{1}}{\mathrm{~d}^{\prime \prime}\left(\mathrm{a}\left(\mathrm{t}_{1}\right)\right)}>\frac{\mathrm{t}_{2}}{\mathrm{~d}^{\prime \prime}\left(\mathrm{a}\left(\mathrm{t}_{2}\right)\right)^{\prime}}$.

so, $\mathrm{Y}_{2}>0$.After simplifying $\mathrm{Y}_{1}$, we get:

$$
\begin{gathered}
Y_{1}=p^{4} I_{1}\left(t_{1}\right) I_{1}\left(t_{2}\right)\left[a\left(t_{2}\right)-a\left(t_{1}\right)\right] \\
-w^{2}(\lambda-1)^{2}\left(w^{2}-w(p-w)(w-c)\right) I_{2}\left(t_{1}\right) I_{2}\left(t_{2}\right)\left[a\left(t_{2}\right)-a\left(t_{1}\right)\right]
\end{gathered}
$$

Since $\frac{\mathrm{da}^{*}}{\mathrm{dt}}=-\frac{1}{\mathrm{p}-\mathrm{w}} \frac{1}{\mathrm{~d}^{\prime \prime}(\mathrm{a}(\mathrm{t}))^{\prime}}$, we conclude: $\frac{\mathrm{da}^{*}}{\mathrm{dt}}>0, \mathrm{a}(\mathrm{t})$ is increasing in $\mathrm{t}$.

so, $a\left(t_{2}\right)>a\left(t_{1}\right)$. Since $I_{1}\left(t_{1}\right) \geq 0 ; I_{1}\left(t_{2}\right) \geq 0 ; I_{2}\left(t_{1}\right) \geq 0 ; I_{2}\left(t_{2}\right) \geq 0$.

so, If $\mathrm{w}^{2}-\mathrm{w}(\mathrm{p}-\mathrm{w})(\mathrm{w}-\mathrm{c})<0 \Rightarrow w<(\mathrm{p}-\mathrm{w})(\mathrm{w}-\mathrm{c})$, then $\mathrm{Y}_{1}>0$.

$\Rightarrow X\left(t_{1}\right)-X\left(t_{2}\right)>0, X(t)$ is decreasing int.

$\Rightarrow \frac{d^{2} E\left(\pi_{M}\right)}{d t^{2}}<0, E\left(\pi_{M}\right)$ is concave function with respect to $t$.

We can get: when $\mathrm{w}<(\mathrm{p}-\mathrm{w})(\mathrm{w}-\mathrm{c})$, there must be the unique Stackelberg equilibrium.

According to the analysis and research above, we find that we can capture the equilibrium solution through analytical characterization when the loss averse retailer and the manufacturer carry out cooperative advertising, so as to bring the convenience for the study of the manufacturer and the retailer's optimal decision. In order to analyze the property of the optimal solution of the decision maker and get more insight, We perform sensitivity analysis of the parameters in the following section 4, moreover, we will also use the numerical analysis method in the latter section 5 to verify the result.

\section{Sensitivity Analysis}

In this section, we theoretically analyze the effects of various parameters about the optimal order quantity and the optimal local advertising investment in the downstream retailer's loss aversion level. In the next section, we use the numerical example to analyze the sensitivity of the parameters to the optimal national advertising investment and the optimal proportion of the upstream manufacturer.

Proposition 1. $\frac{\partial \mathrm{q}^{*}}{\partial \lambda}<0 ; \frac{\partial \mathrm{a}^{*}}{\partial \lambda}>0$.

\section{Proof of Proposition 1}

By the implicit function theorem, $\frac{\partial \mathrm{q}^{*}}{\partial \lambda}=-\frac{\partial^{2} \mathrm{E}\left(\mathrm{U}\left(\pi_{\mathrm{R}}\right)\right)}{\partial \mathrm{q}^{*} \partial \lambda} / \frac{\partial^{2} \mathrm{E}\left(\mathrm{U}\left(\pi_{\mathrm{R}}\right)\right)}{\partial \mathrm{q}^{* 2}}$. From (8), we get:

$$
\frac{\partial^{2} \mathrm{E}\left(\mathrm{U}\left(\pi_{\mathrm{R}}\right)\right)}{\partial \mathrm{q}^{*} \partial \lambda}=-w F\left(\mathrm{q}^{*}-\mathrm{d}(\mathrm{a})\right)<0
$$

since $\frac{\partial^{2} \mathrm{E}\left(\mathrm{U}\left(\pi_{\mathrm{R}}\right)\right)}{\partial \mathrm{q}^{* 2}}=-p f\left(\mathrm{q}^{*}-\mathrm{d}\left(\mathrm{a}^{*}\right)\right)-\frac{\mathrm{w}^{2}}{\mathrm{p}}(\lambda-1) \mathrm{f}\left(\mathrm{q}_{1}\left(\mathrm{q}^{*}, \mathrm{a}^{*}\right)-\mathrm{d}\left(\mathrm{a}^{*}\right)\right)<0$,

so, $\frac{\partial \mathrm{q}^{*}}{\partial \lambda}<0$ and $\mathrm{q}^{*}$ is strictly decreasing in $\lambda$. 
Similarly, $\frac{\partial \mathrm{a}^{*}}{\partial \lambda}=-\frac{\partial^{2} \mathrm{E}\left(\mathrm{U}\left(\pi_{\mathrm{R}}\right)\right)}{\partial \mathrm{a}^{*} \partial \lambda} / \frac{\partial^{2} \mathrm{E}\left(\mathrm{U}\left(\pi_{\mathrm{R}}\right)\right)}{\partial \mathrm{a}^{* 2}}$, By (9), we get:

$$
\begin{gathered}
\frac{\partial^{2} \mathrm{E}\left(\mathrm{U}\left(\pi_{\mathrm{R}}\right)\right)}{\partial \mathrm{a}^{*} \partial \lambda}=\left[\mathrm{pd}^{\prime}\left(\mathrm{a}^{*}\right)-(1-\mathrm{t})\right] \mathrm{F}\left(\mathrm{q}_{1}\left(\mathrm{q}^{*}, \mathrm{a}^{*}\right)-\mathrm{d}\left(\mathrm{a}^{*}\right)\right) \\
\begin{aligned}
& \frac{\partial^{2} \mathrm{E}\left(\mathrm{U}\left(\pi_{\mathrm{R}}\right)\right)}{\partial \mathrm{a}^{* 2}}=\mathrm{pd}^{\prime \prime}\left(\mathrm{a}^{*}\right) \mathrm{F}\left(\mathrm{q}^{*}-\mathrm{d}\left(\mathrm{a}^{*}\right)\right)-\mathrm{p}\left(\mathrm{d}^{\prime}\left(\mathrm{a}^{*}\right)\right)^{2} \mathrm{f}\left(\mathrm{q}^{*}-\mathrm{d}\left(\mathrm{a}^{*}\right)\right) \\
&+(\lambda-1) p d^{\prime \prime}\left(\mathrm{a}^{*}\right) \mathrm{F}\left(\mathrm{q}_{1}\left(\mathrm{q}^{*}, \mathrm{a}^{*}\right)-\mathrm{d}\left(\mathrm{a}^{*}\right)\right) \\
&+(\lambda-1)\left[\mathrm{pd}^{\prime}\left(\mathrm{a}^{*}\right)-(1-\mathrm{t})\right] \mathrm{f}\left(\mathrm{q}_{1}\left(\mathrm{q}^{*}, \mathrm{a}^{*}\right)-\mathrm{d}\left(\mathrm{a}^{*}\right)\right)\left[\frac{1-\mathrm{t}}{\mathrm{p}}-\mathrm{d}^{\prime}\left(\mathrm{a}^{*}\right)\right]
\end{aligned}
\end{gathered}
$$

Since $d^{\prime}\left(a^{*}\right)=\frac{1-t}{p-w}>0, d^{\prime \prime}\left(a^{*}\right)<0, \frac{p}{p-w}-1>0$ and $\frac{1}{p}-\frac{1}{p-w}<0$.

we can obtain:

$$
\begin{gathered}
\frac{\partial^{2} \mathrm{E}\left(\mathrm{U}\left(\pi_{\mathrm{R}}\right)\right)}{\partial \mathrm{a}^{*} \partial \lambda}=\left(\frac{\mathrm{p}}{\mathrm{p}-\mathrm{w}}-1\right)(1-\mathrm{t}) \mathrm{F}\left(\mathrm{q}_{1}\left(\mathrm{q}^{*}, \mathrm{a}^{*}\right)-\mathrm{d}\left(\mathrm{a}^{*}\right)\right)>0 ; \\
\frac{\partial^{2} \mathrm{E}\left(\mathrm{U}\left(\pi_{\mathrm{R}}\right)\right)}{\partial \mathrm{a}^{*^{2}}}=\mathrm{pd}^{\prime \prime}\left(\mathrm{a}^{*}\right) \mathrm{F}\left(\mathrm{q}^{*}-\mathrm{d}\left(\mathrm{a}^{*}\right)\right)-\mathrm{p}\left(\mathrm{d}^{\prime}\left(\mathrm{a}^{*}\right)\right)^{2} \mathrm{f}\left(\mathrm{q}^{*}-\mathrm{d}\left(\mathrm{a}^{*}\right)\right) \\
+\mathrm{p}(\lambda-1) \mathrm{d}^{\prime \prime}\left(\mathrm{a}^{*}\right) \mathrm{F}\left(\mathrm{q}_{1}\left(\mathrm{q}^{*}, \mathrm{a}^{*}\right)-\mathrm{d}\left(\mathrm{a}^{*}\right)\right) \\
+(\lambda-1)\left(\frac{\mathrm{p}}{\mathrm{p}-\mathrm{w}}-1\right)(1-\mathrm{t})^{2} \mathrm{f}\left(\mathrm{q}_{1}\left(\mathrm{q}^{*}, \mathrm{a}^{*}\right)-\mathrm{d}\left(\mathrm{a}^{*}\right)\right)\left(\frac{1}{\mathrm{p}}-\frac{1}{\mathrm{p}-\mathrm{w}}\right)<0
\end{gathered}
$$

so, $\frac{\partial \mathrm{a}^{*}}{\partial \lambda}>0$, and $\mathrm{a}^{*}$ is increasing in $\lambda$.

Proposition 1 show that, if the retailer's loss aversion level is higher, the retailer will reduce the order quantity due to fear of loss. However, It is interesting that the loss averse retailer will increase local advertising investment with the increasing of loss aversion level, thereby promoting the growth of market demand. There will be such a result, perhaps because of that the upstream manufacturer will participate the local advertising cost of the downstream retailer. The reality also tell us that the higher the degree of loss aversion, the retailer is more sensitive to loss, in order to avoid the potential losses, the retailer will reduce the order quantity. On the other hand, the retailer maybe increase investment in local advertising because the upstream manufacturer will bear the risk of the retailer's local advertising loss.

Corollary1.1 If the manufacturer and the retailer carry out cooperate advertising, the loss averse retailer will always order less than the risk neutral retailer;(2)If the manufacturer and the retailer carry out cooperate advertising, the optimal local advertising expenditure of the retailer in loss averse is always larger than the optimal local advertising expenditure of the risk neutral retailer.

\section{Proof of Corollary}

(1)From Proposition 1, we know that the optimal order quantity of the loss averse retailer is decreasing with loss aversion level, and if $\lambda=1$,then the retailer is risk neutral. We also know $\lambda \geq 1$. so, when the loss aversion level $\lambda=1$, the optimal order quantity of the retailer is the maximum. that is, the optimal order quantity of the retailer in loss averse is always less than the optimal order quantity of the risk neutral retailer.

(2)Similar proof to (1), we know that the optimal local advertising expenditure of the loss averse retailer is increasing with loss aversion level, and if $\lambda=1$,then the retailer is risk neutral. Since $\lambda \geq 1$, so, when the loss aversion level $\lambda=1$, the optimal order quantity of the retailer is the minimum. that is, the optimal 
local advertising expenditure of the retailer in loss averse is always larger than the optimal local advertising expenditure of the risk neutral retailer.

The result of Corollary (1) is similar to a result in the literature[9]-[10], where analyzing the optimal order quantity of the newsvendor.

Proposition 2. $\frac{\partial \mathrm{q}^{*}}{\partial \mathrm{a}^{*}}>0$. The loss averse retailer's optimal order quantity increase as the optimal local advertising expenditure increases.

\section{Proof of Proposition2}

By the implicit function theorem, $\frac{\partial \mathrm{q}^{*}}{\partial \mathrm{a}^{*}}=-\frac{\left.\partial^{2} \mathrm{E}\left(\mathrm{U}\left(\pi_{\mathrm{R}}\right)\right)\right)}{\partial \mathrm{q}^{*} \partial \mathrm{a}^{*}} / \frac{\left.\partial^{2} \mathrm{E}\left(\mathrm{U}\left(\pi_{\mathrm{R}}\right)\right)\right)}{\partial \mathrm{q}^{* 2}}$,

since $\frac{\partial^{2} \mathrm{E}\left(\mathrm{U}\left(\pi_{\mathrm{R}}\right)\right)}{\partial \mathrm{q}^{*} \partial \mathrm{a}^{*}}=\operatorname{pf}\left(\mathrm{q}^{*}-\mathrm{d}\left(\mathrm{a}^{*}\right)\right) \mathrm{d}^{\prime}\left(\mathrm{a}^{*}\right)$

$$
-w(\lambda-1)(1-t) f\left(q_{1}\left(q^{*}, a^{*}\right)-d\left(a^{*}\right)\right)\left(\frac{1}{p}-\frac{1}{p-w}\right)>0
$$

According to the proof ofproposition $1, \frac{\partial^{2} \mathrm{E}\left(\mathrm{U}\left(\pi_{R}\right)\right)}{\partial \mathrm{q}^{* 2}}<0$. Therefore, we can get: $\frac{\partial \mathrm{q}^{*}}{\partial \mathrm{a}^{*}}>0$.

Proposition 3. $\frac{\mathrm{da}^{*}}{\mathrm{dt}}>0, \frac{\mathrm{dq}^{*}}{\mathrm{dt}}>0$. The optimal order quantity and the optimal local advertising expenditure of the loss averse retailer is increasing in the participation rate.

Proof of Proposition 3

Since $\frac{\mathrm{da}^{*}}{\mathrm{dt}}=-\frac{1}{\mathrm{p}-\mathrm{w}} \frac{1}{\mathrm{~d}^{\prime \prime}(\mathrm{a}(\mathrm{t}))} ; \frac{\mathrm{dq}^{*}}{\mathrm{dt}}=\frac{\mathrm{M}(\mathrm{t})}{\mathrm{K}(\mathrm{t})}$

where

$$
\begin{gathered}
M(t)=w(p-w)(\lambda-1) d^{\prime \prime}(a(t)) a(t) I_{2}(t)-d^{\prime}(a(t))\left[p^{2} I_{1}(t)+w^{2}(\lambda-1) I_{2}(t)\right] ; \\
K(t)=(p-w) d^{\prime \prime}(a(t))\left[p^{2} I_{1}(t)+w^{2}(\lambda-1) I_{2}(t)\right] ; \\
I_{1}(t)=f(q(t)-d(a(t))) ; I_{2}(t)=f\left(q_{1}(q(t), a(t))-d(a(t))\right)
\end{gathered}
$$

$d(a)$ is concave function with respect to aand increasing in a. we can get:

$d^{\prime}(a(t))>0$ and $d^{\prime \prime}(a(t))<0$, furthermore, $I_{1}(t)>0, I_{2}(t)>0$.

then $\mathrm{K}(\mathrm{t})<0, \mathrm{M}(\mathrm{t})<0$.

Hence, $\frac{\mathrm{da}^{*}}{\mathrm{dt}}>0, \frac{\mathrm{dq}^{*}}{\mathrm{dt}}>0$. That is, the retailer's optimal order quantity and local advertising expenditure is increasing in the upstream manufacturer's participation rate.

Proposition 2 indicate that the retailer will increase the order quantity if the retailer enhance the local advertising expenditure despite he is loss averse. When the retailer increase the advertising expenditure, it will boost the market demand, hence, the retailer is certain to order more product. From proposition 3, If the upstream manufacturer give the downstream retailer more share of advertising cost, the retailer will synchronously increase the order quantity and the advertising expenditure. This is because, the more the proportion rate, the less the potential loss of retailers, the retailer are willing to increase the advertising expenditure and order quantity, so as to enhance the performance of the supply chain.

Proposition 4. $\frac{\mathrm{d}^{2} \mathrm{a}^{*}}{\mathrm{dt}^{2}}>0$; If density function of the noise esatisfy $\mathrm{f}^{\prime}(\mathrm{x})=0$, then $\frac{\mathrm{d}^{2} \mathrm{q}^{*}}{\mathrm{dt}^{2}}>0$.

\section{Proof of Proposition4}

First, since $\frac{\mathrm{da}^{*}}{\mathrm{dt}}=-\frac{1}{\mathrm{p}-\mathrm{w}} \frac{1}{\mathrm{~d}^{\prime \prime}(\mathrm{a}(\mathrm{t}))^{\prime}}$, we get: $\frac{\mathrm{d}^{2} \mathrm{a}^{*}}{\mathrm{dt}^{2}}=\frac{1}{\mathrm{p}-\mathrm{w}} \frac{\mathrm{d}^{\prime \prime \prime}(\mathrm{a}(\mathrm{t}))}{\left(\mathrm{d}^{\prime \prime}(\mathrm{a}(\mathrm{t}))\right)^{2}} \frac{\mathrm{da}^{*}}{\mathrm{dt}}=-\frac{1}{(\mathrm{p}-\mathrm{w})^{2}} \frac{\mathrm{d}^{\prime \prime \prime}(\mathrm{a}(\mathrm{t}))}{\left(\mathrm{d}^{\prime \prime}(\mathrm{a}(\mathrm{t}))\right)^{3}}$. 
Based on the assume given in section2, $\mathrm{d}^{\prime \prime \prime}(\mathrm{a}(\mathrm{t}))>0$, hence, $\frac{\mathrm{d}^{2} \mathrm{a}^{*}}{\mathrm{dt}^{2}}>0$.

Next, we discuss $\frac{\mathrm{d}^{2} \mathrm{q}^{*}}{\mathrm{dt}^{2}}$. we let $\mathrm{G}(\mathrm{t})=\frac{\mathrm{dq}^{*}}{\mathrm{dt}}=\frac{\mathrm{M}(\mathrm{t})}{\mathrm{K}(\mathrm{t})}$, where

$$
\begin{gathered}
M(t)=w(p-w)(\lambda-1) d^{\prime \prime}(a(t)) a(t) I_{2}(t)-d^{\prime}(a(t))\left[p^{2} I_{1}(t)+w^{2}(\lambda-1) I_{2}(t)\right] ; \\
K(t)=(p-w) d^{\prime \prime}(a(t))\left[p^{2} I_{1}(t)+w^{2}(\lambda-1) I_{2}(t)\right] . \quad \forall 0 \leq t_{1}<t_{2} \leq 1 \\
G\left(t_{1}\right)=\frac{M\left(t_{1}\right)}{K\left(t_{1}\right)}=\frac{w(p-w)(\lambda-1) d^{\prime \prime}\left(a\left(t_{1}\right)\right) a\left(t_{1}\right) I_{2}\left(t_{1}\right)-d^{\prime}\left(a\left(t_{1}\right)\right)\left[p^{2} I_{1}\left(t_{1}\right)+w^{2}(\lambda-1) I_{2}\left(t_{1}\right)\right]}{(p-w) d^{\prime \prime}\left(a\left(t_{1}\right)\right)\left[p^{2} I_{1}\left(t_{1}\right)+w^{2}(\lambda-1) I_{2}\left(t_{1}\right)\right]} \\
G\left(t_{2}\right)=\frac{M\left(t_{2}\right)}{K\left(t_{2}\right)}=\frac{w(p-w)(\lambda-1) d^{\prime \prime}\left(a\left(t_{2}\right)\right) a\left(t_{2}\right) I_{2}\left(t_{2}\right)-d^{\prime}\left(a\left(t_{2}\right)\right)\left[p^{2} I_{1}\left(t_{2}\right)+w^{2}(\lambda-1) I_{2}\left(t_{2}\right)\right]}{(p-w) d^{\prime \prime}\left(a\left(t_{2}\right)\right)\left[p^{2} I_{1}\left(t_{2}\right)+w^{2}(\lambda-1) I_{2}\left(t_{2}\right)\right]}
\end{gathered}
$$

so, we get:

$$
G\left(t_{1}\right)-G\left(t_{2}\right)=\frac{M\left(t_{1}\right)}{K\left(t_{1}\right)}-\frac{M\left(t_{2}\right)}{K\left(t_{2}\right)}=\frac{M\left(t_{1}\right) K\left(t_{2}\right)-M\left(t_{2}\right) K\left(t_{1}\right)}{K\left(t_{1}\right) K\left(t_{2}\right)}
$$

we note $\mathrm{u}_{1}=\mathrm{p}^{2} \mathrm{I}_{1}\left(\mathrm{t}_{1}\right)+\mathrm{w}^{2}(\lambda-1) \mathrm{I}_{2}\left(\mathrm{t}_{1}\right)$ and $\mathrm{u}_{2}=\mathrm{p}^{2} \mathrm{I}_{1}\left(\mathrm{t}_{2}\right)+\mathrm{w}^{2}(\lambda-1) \mathrm{I}_{2}\left(\mathrm{t}_{2}\right)$ then,

$$
\begin{gathered}
M\left(t_{1}\right) K\left(t_{2}\right)-M\left(t_{2}\right) K\left(t_{1}\right)= \\
w(p-w)^{2}(\lambda-1) d^{\prime \prime}\left(a\left(t_{1}\right)\right) d^{\prime \prime}\left(a\left(t_{2}\right)\right)\left[a\left(t_{1}\right) I_{2}\left(t_{1}\right) u_{2}-a\left(t_{2}\right) I_{2}\left(t_{2}\right) u_{1}\right] \\
+(p-w) u_{1} u_{2}\left[d^{\prime \prime}\left(a\left(t_{1}\right)\right) d^{\prime}\left(a\left(t_{2}\right)\right)-d^{\prime \prime}\left(a\left(t_{2}\right)\right) d^{\prime}\left(a\left(t_{1}\right)\right)\right] .
\end{gathered}
$$

From the proposition $3, \mathrm{a}(\mathrm{t})$ is increasing with t. so, $\mathrm{a}\left(\mathrm{t}_{2}\right)>a\left(\mathrm{t}_{1}\right)$.

moreover, $\left(d^{\prime}(a(t))\right)^{\prime}=d^{\prime \prime}(a(t)) \frac{d a^{*}}{d t}<0,\left(d^{\prime \prime}(a(t))\right)^{\prime}=d^{\prime \prime \prime}(a(t)) \frac{d a^{*}}{d t}>0$.

therefore, $d^{\prime}\left(a\left(t_{2}\right)\right)<d^{\prime}\left(a\left(t_{1}\right)\right)$ and $d^{\prime \prime}\left(a\left(t_{1}\right)\right)<d^{\prime \prime}\left(a\left(t_{2}\right)\right)$.

we can get: $d^{\prime \prime}\left(a\left(t_{1}\right)\right) d^{\prime}\left(a\left(t_{2}\right)\right)-d^{\prime \prime}\left(a\left(t_{2}\right)\right) d^{\prime}\left(a\left(t_{1}\right)\right)<0$.

We cannot judge the relationship between $a\left(t_{1}\right) I_{2}\left(t_{1}\right) u_{2}$ and $a\left(t_{2}\right) I_{2}\left(t_{2}\right) u_{1}$.so, whether $G\left(t_{1}\right)-G\left(t_{2}\right)$ is greater than 0 cannot be determined (i.e., $G(t)$ may increase withtand maybe decrease with $t$ ).However, we find that, when density function of the noise $\varepsilon$ satisfy $\mathrm{f}^{\prime}(\mathrm{x})=0$ (for example, the market demand follows the uniform distribution).

then, $\mathrm{I}_{2}\left(\mathrm{t}_{1}\right)=\mathrm{I}_{2}\left(\mathrm{t}_{2}\right)$ and $\mathrm{u}_{1}=\mathrm{u}_{2} \Rightarrow \mathrm{a}\left(\mathrm{t}_{1}\right) \mathrm{I}_{2}\left(\mathrm{t}_{1}\right) \mathrm{u}_{2}-\mathrm{a}\left(\mathrm{t}_{2}\right) \mathrm{I}_{2}\left(\mathrm{t}_{2}\right) \mathrm{u}_{1}<0$

so, $G\left(t_{1}\right)-G\left(t_{2}\right)<0$. That is, $G(t)$ is increasing in t.there must be: $\frac{d^{2} q^{*}}{{d t^{2}}^{2}}>0$.

Proposition 5. $\frac{\partial \mathrm{q}^{*}}{\partial \mathrm{p}}>0, \frac{\partial \mathrm{q}^{*}}{\partial \mathrm{w}}<0, \frac{\partial \mathrm{a}^{*}}{\partial \mathrm{p}}>0, \frac{\partial \mathrm{a}^{*}}{\partial \mathrm{w}}<0$; When $\mathrm{w}<(\mathrm{p}-\mathrm{w})(\mathrm{w}-\mathrm{c})$, then $\frac{\partial \mathrm{t}^{*}}{\partial \mathrm{c}}<0$.

By the implicit function theorem, we get:

$$
\frac{\partial \mathrm{q}^{*}}{\partial \mathrm{p}}=-\frac{\partial^{2} \mathrm{E}\left(\mathrm{U}\left(\pi_{\mathrm{R}}\right)\right)}{\partial \mathrm{q}^{*} \partial \mathrm{p}} / \frac{\partial^{2} \mathrm{E}\left(\mathrm{U}\left(\pi_{\mathrm{R}}\right)\right)}{\partial \mathrm{q}^{* 2}} ; \frac{\partial \mathrm{q}^{*}}{\partial \mathrm{w}}=-\frac{\partial^{2} \mathrm{E}\left(\mathrm{U}\left(\pi_{\mathrm{R}}\right)\right)}{\partial \mathrm{q}^{*} \partial \mathrm{w}} / \frac{\partial^{2} \mathrm{E}\left(\mathrm{U}\left(\pi_{\mathrm{R}}\right)\right)}{\partial \mathrm{q}^{* 2}}
$$

by(8), we can conclude: $\frac{\partial^{2} \mathrm{E}\left(\mathrm{U}\left(\pi_{\mathrm{R}}\right)\right)}{\partial \mathrm{q}^{*} \partial \mathrm{p}}=1-\mathrm{F}(\mathrm{q}-\mathrm{d}(\mathrm{a}))>0 ; \frac{\partial^{2} \mathrm{E}\left(\mathrm{U}\left(\pi_{\mathrm{R}}\right)\right)}{\partial \mathrm{q}^{*} \partial \mathrm{w}}=-1-(\lambda-1) \mathrm{F}\left(\mathrm{q}_{1}-\mathrm{d}(\mathrm{a})\right)<0$. since $\frac{\partial^{2} \mathrm{E}\left(\mathrm{U}\left(\pi_{\mathrm{R}}\right)\right)}{\partial \mathrm{q}^{* 2}}>0$, so, $\frac{\partial \mathrm{q}^{*}}{\partial \mathrm{p}}>0$ and $\frac{\partial \mathrm{q}^{*}}{\partial \mathrm{w}}<0$. Similarly, we can conclude: $\frac{\partial \mathrm{a}^{*}}{\partial \mathrm{p}}>0$ and $\frac{\partial \mathrm{a}^{*}}{\partial \mathrm{w}}<0$. 


$$
\frac{\partial \mathrm{t}^{*}}{\partial \mathrm{c}}=-\frac{\partial^{2} \mathrm{E}\left(\mathrm{U}\left(\pi_{\mathrm{M}}\right)\right)}{\partial \mathrm{t}^{*} \partial \mathrm{c}} / \frac{\partial^{2} \mathrm{E}\left(\mathrm{U}\left(\pi_{\mathrm{M}}\right)\right)}{\partial \mathrm{t}^{* 2}}
$$

According to the proof of Theorem 4, when $w<(p-w)(w-c), \frac{\partial^{2} E\left(U\left(\pi_{M}\right)\right)}{\partial t^{* 2}}<0$.

we get: $\frac{\partial^{2} \mathrm{E}\left(\mathrm{U}\left(\pi_{\mathrm{M}}\right)\right)}{\partial \mathrm{t}^{*} \partial \mathrm{c}}=-\frac{\mathrm{M}\left(\mathrm{t}^{*}\right)}{\mathrm{K}\left(\mathrm{t}^{*}\right)}<0$.Therefore, If $\mathrm{w}<(\mathrm{p}-\mathrm{w})(\mathrm{w}-\mathrm{c})$, then $\frac{\partial \mathrm{t}^{*}}{\partial \mathrm{c}}<0$.

Proposition 5 indicates that the optimal order quantity and the optimal advertising investment of the loss averse retailer is decreasing in retail price, while is increasing in whole price of the product; under the certain conditions, the manufacturer's optimal participation rate is increasing in product's manufacturing cost. When the retail price of the product is higher, the loss averse retailer will strengthen cooperation with manufacturers to increase the order quantity. On the other hand, if the wholesale price of the product is higher, based on the psychology of loss aversion, the retailer will reduce the amount of product order. Meanwhile, as the marginal profit is lower, manufacturers will also reduce the proportion of the downstream retailer to share. It is difficult to analyze how the upstream manufacturer's optimal sharing ratio $t^{*}$ change with the downstream retailer's loss aversion level $\lambda$, we will conduct anumerical analysis in section 5 .

\section{Numerical Analysis}

In this section, we will analyze the regular pattern of the upstream and downstream enterprise's optimal decisions with the parameter change by numerical example. At the same time, we use numerical examples to further explain the effect on the supply chain cooperative advertising when the downstream retailer is loss averse.

We assume the market demand function $(a)=a_{0}+k \sqrt{a}$, where $a_{0}>0$ represents the product's potential demand, $\mathrm{k}>0$ represents the sensitivity of the demand for the local advertising investment. The demand function is a square root function, this form of demand function has been widely used in a large number of literatures [21], [24]. We let $\mathrm{a}_{0}=1$ and $\mathrm{k}=0.7$. Following the condition of theorem 4 ,we set $\mathrm{p}=10, \mathrm{w}=6, \mathrm{c}=3$.The random perturbation on the market demand, $\varepsilon$,is assumed to follow the uniform distribution on $[-1,1]$ in order to ensure that the mean value of $\varepsilon$ is 0 . According to the analysis given in the previous section 4 , we have obtained the variation law of the retailer's optimal decision with the degree of loss aversion, the following we proceed to use numerical example to analyze how the manufacturer's optimal participation rate changes with the level of loss aversion, and the result is shown in Fig. 1.

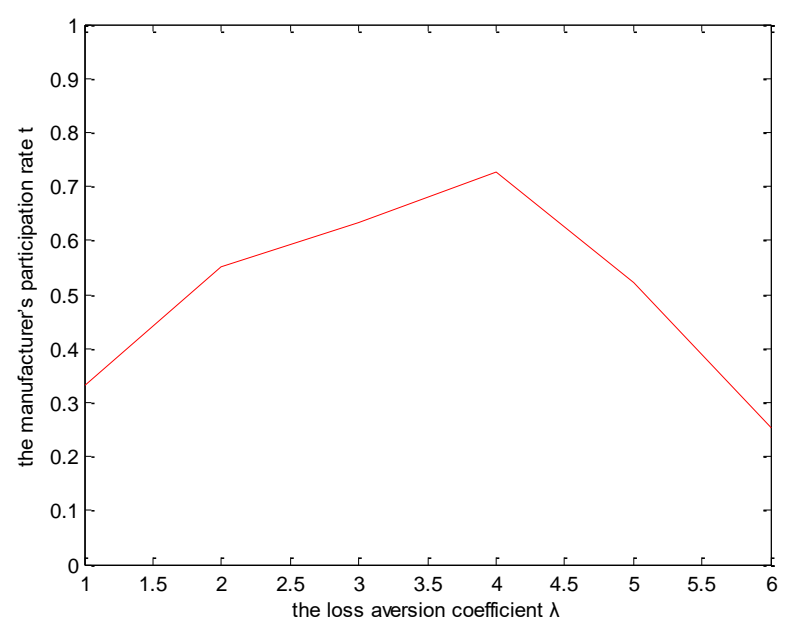

Fig. 1. How tchange with $\lambda$. 
Fig. 1 tell us, when the retailer's loss aversion is greater, the manufacturer participation rate that manufacturer agrees to pay the retailer is unimodal, it increases up to a certain level of loss aversion and decreases after that. Of course, if the loss aversion level is too large, the manufacturer will not share the retailer's advertising cost, that is the manufacturer will stop cooperative advertising with the retailer. The result has useful practical implications, in real life, in order to stimulate the market demand, if the upstream manufacturer carry out cooperative advertising with the downstream retailer, then the manufacturer must consider the risk attitude of the downstream retailers .Fig 1 also reveal that the increasing rate of the participation rate is less than the decreasing rate of the participation rate, this show that when the upstream manufacturer find the loss aversion level of the upstream retailer is too bigger, the manufacturer will accelerate the reduction of the advertising subsidies to the retailer, until the participation rate is 0 .

We let the wholesale price $\mathrm{w}=6$, the retail price pincrease from 10 to 20 ; as well as the retail price $\mathrm{p}=10$ and the wholesale price wchange from 6 to 8 , respectively.The values of the other parameters are the same as in the previous, and the results shown in Fig. 2 can be obtained.
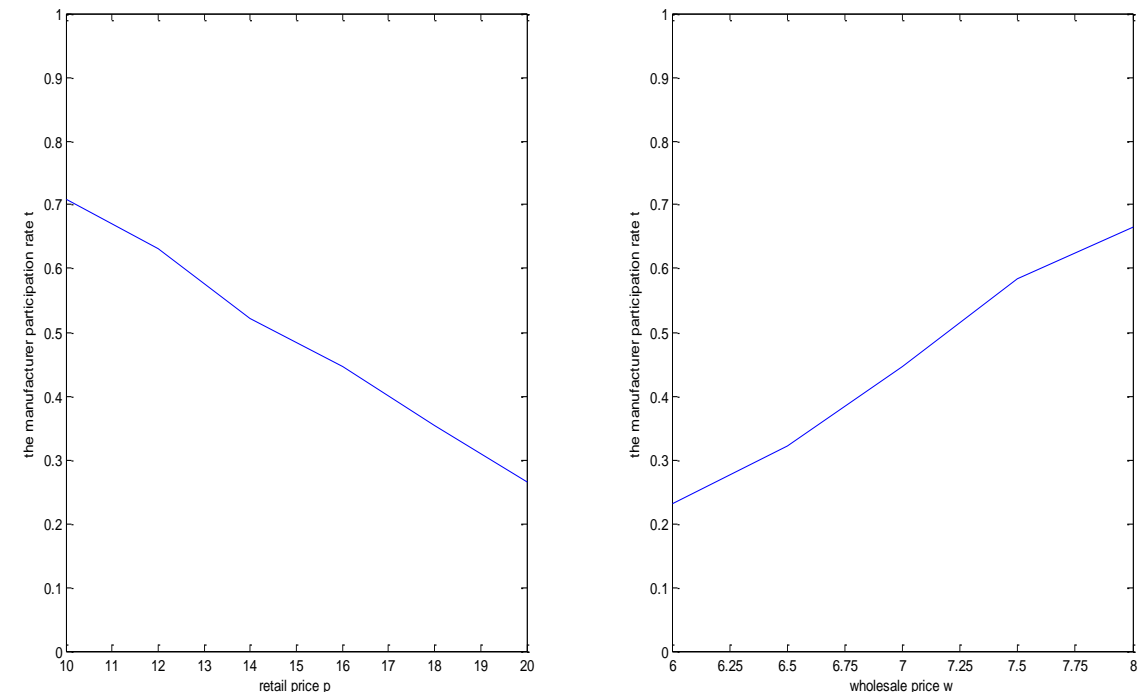

Fig. 2. How $t$ change with $p$ and $w$.

Fig. 2 show that the upstream manufacturer's optimal decision decrease as the retail price increases; and also increase as the whole price increases. When the retail price increases, the margin profit of the retailer are also correspondingly increased, so, without the upstream manufacturers sharing too much advertising cost ,the retailer prefer to increase local advertising investment in the case of profitable .On the other hand, the participation rate of the manufacturer decrease as the retail price increases. Similarly, the bigger the wholesale price, the more marginal profit of the manufacturer, this will stimulate the upstream manufacturer to increase the participation rate of advertising expenditure for the downstream retailer to promote the growth of demand in order to get more profit. It also tells us that when the upstream manufacturer's profit margin is higher, due to the upstream manufacturer maybe give a higher advertising cost sharing and the downstream retailers will increase the local advertising expenditure, so as to achieve a win-win situation, while enhance the performance of the supply chain.

We let the retailer's loss aversion coefficient $\lambda=1.5$ and $\lambda=2$, respectively. Compared to the case that the retailer is risk neutral (i.e., $\lambda=1$ ). When the retail price pvaries from 10 to 20 , as well as wholesale price wincrease from 6 to 8 , and the values of the other parameters are constant, the optimal decision curves of the retailer are showed in Fig. 3-Fig. 6. 


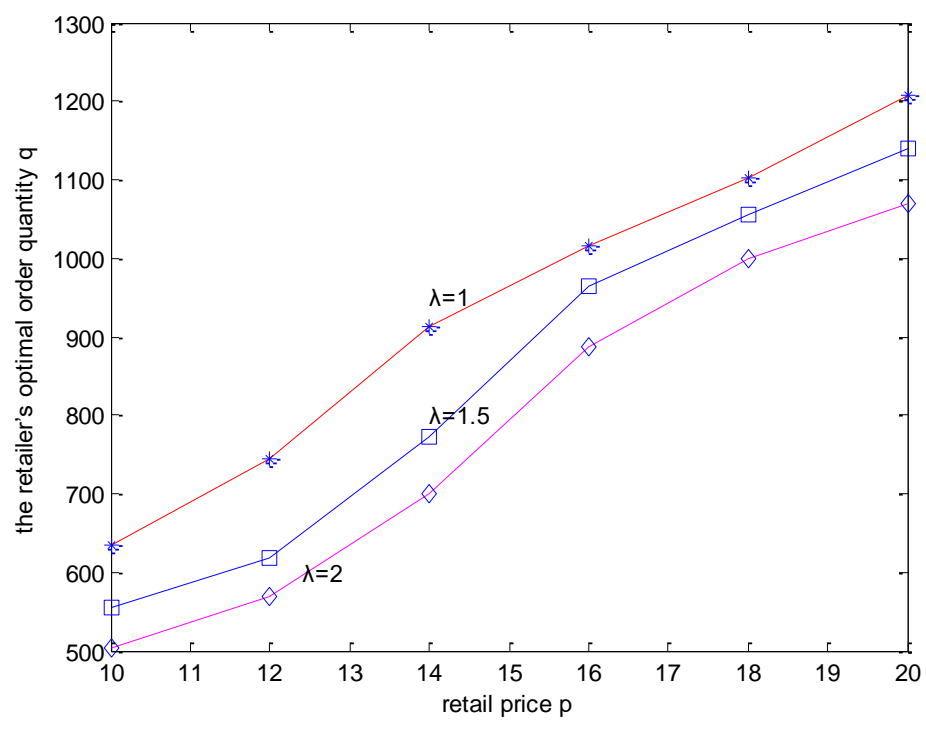

Fig. 3. How $q$ change with $p$ and diffrent $\lambda$.

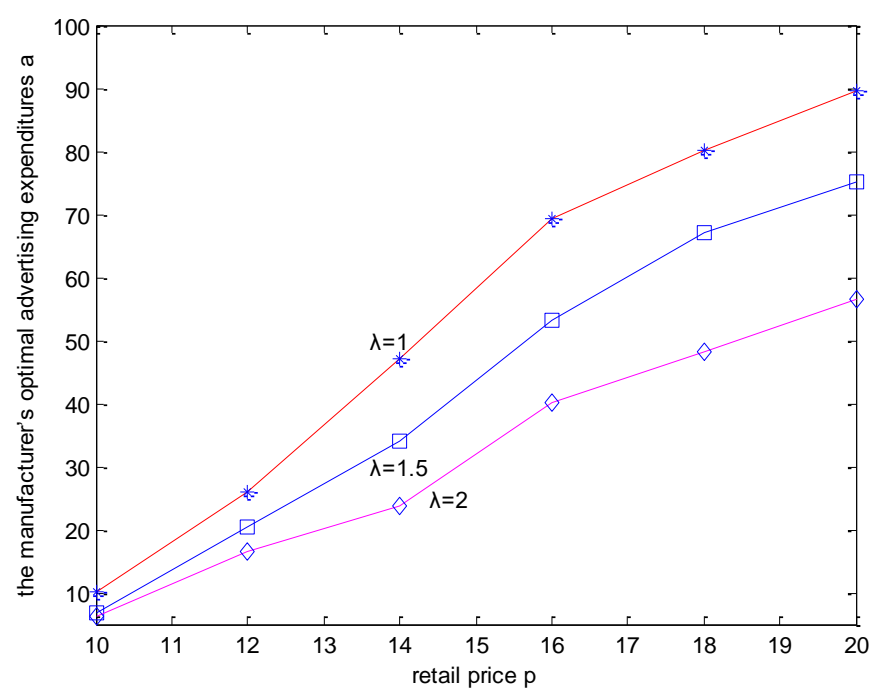

Fig. 4. How a change with $\mathrm{p}$ and $\lambda$.

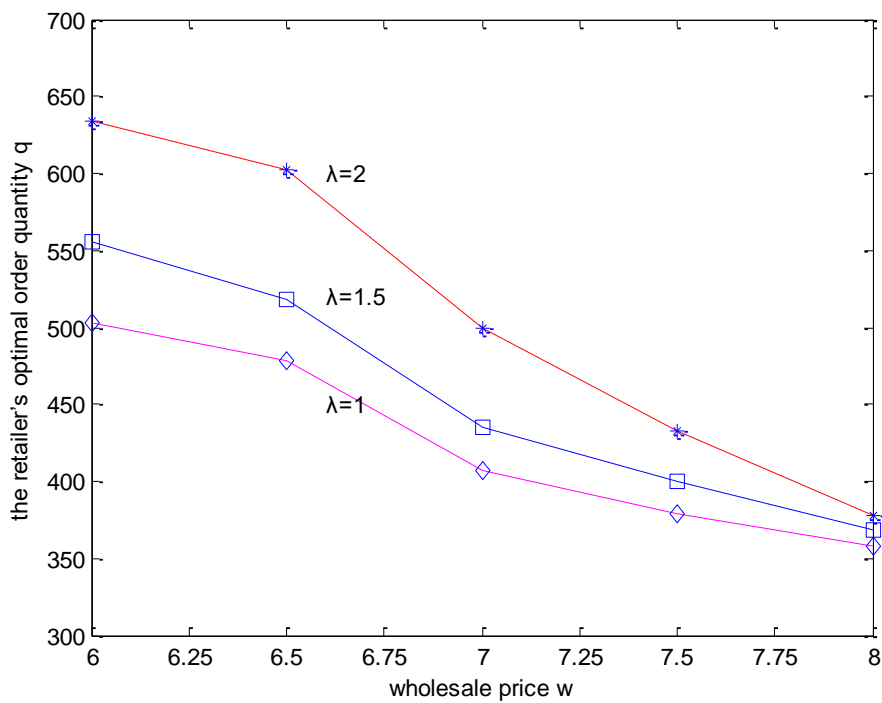

Fig. 5. How q change with $\lambda$. 


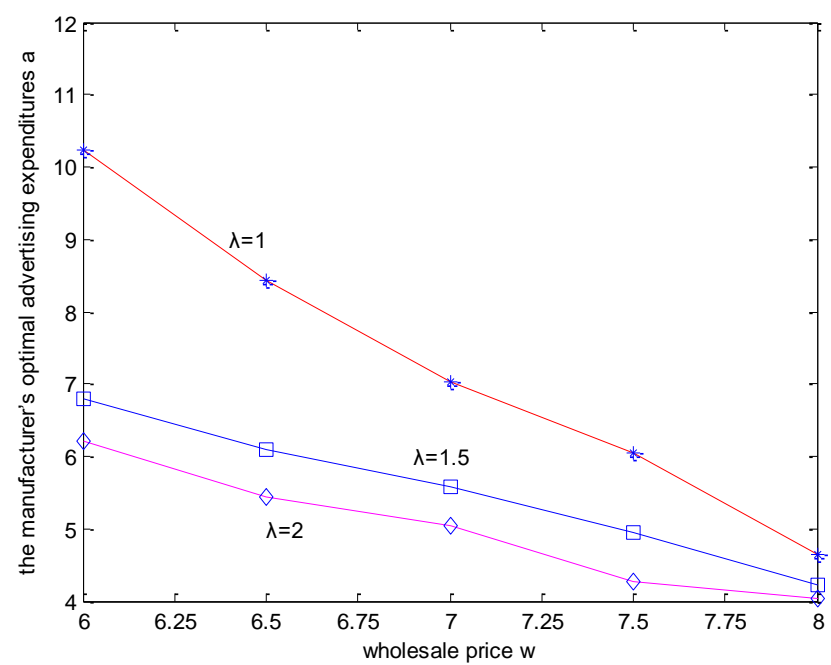

Fig. 6. How a change with $\mathrm{w}$ and $\lambda$.

Fig. 3-Fig. 6 demonstrate the results of proposition 5, it is indicated that the optimal order quantity of the retailer is always increasing with the retail price, and is also decreasing in the wholesale price. At the same time, compared to the optimal decision of the risk neutral retail, the results of numerical example are consistent with the results of the previous corollary, this numerical example further confirm that the optimal order quantity of the retailer in loss averse is always less than the optimal order quantity of the risk neutral retailer, but on the contrary, the optimal local advertising expenditure of the retailer in loss averse is always larger than the optimal local advertising expenditure of the risk neutral retailer.

\section{Conclusion}

In this paper, we study the problem of cooperative advertising under uncertain demand. When the retailer's risk attitude is the loss aversion, on the basis of some existing conclusions, we further analyse and depict the equilibrium solution of the Stackelberg game. We have carried out the sensitivity analysis and the numerical analysis. Through the comparison of the risk neutral retailer and the loss averse retailer's optimal decision, we find that, the optimal order quantity of the retailer in loss averse is always less than the optimal order quantity of the risk neutral retailer; However, because the upstream manufacturer will participate the advertising cost of the downstream retailer, the optimal local advertising expenditure of the retailer in loss averse is always larger than the optimal local advertising expenditure of the risk neutral retailer. Moreover, we also find, when the downstream retailer loss aversion level is higher, the optimal order quantity of the retailer will decreased; the retailer's optimal advertising expenditure increase as the loss aversion level increases. When the upstream manufacturers give the retailer more the proportion of advertising cost, the retailer's optimal order quantity and optimal advertising expenditure will be increased accordingly; but, the manufacturer participation rate that manufacturer agrees to pay the retailer is unimodal, it increases up to a certain loss aversion level and decreases after that, the increasing rate of the participation rate is less than the decreasing rate of the participation rate, When the loss aversion level reaches a certain degree, the manufacturer will stop cooperative advertising with the retailer. In addition, we also investigate how the optimal decision of the supply chain enterprises change by the retail price and the wholesale price, the results are in good agreement with the reality. Some extensions of this study, such as adding the manufacturer's national advertising expenditure as the decision variable. Moreover, future research may find it worthwhile to discuss the equilibrium solution and the coordination mechanisms among the manufacturer and retailers under retailers competition ,if there are multiple retailers . 


\section{Acknowledgment}

I would like to show my deepest gratitude to Prof. JinXin, Xie of Tsinghua University, who has provided me with valuable guidance in this paper. This paper is also supported by foundation of Sichuan Educational Committee(17ZB0015) and foundation of Chengdu Textile College(FZLK2017B04).

\section{References}

[1] Aust, G., \& Buscher, U. (2014). Cooperative advertising models in supply chain management: A review. European Journal of Operational Research, 234(1), 1-14.

[2] He, X., Krishnamoorthy, A., et al. (2011). Retail competition and cooperative advertising. Operations Research Letters, 39(1), 11-16.

[3] Tsao, Y., \& Sheen, G. (2012). Effects of promotion cost sharing policy with the sales learning curve on supply chain coordination. Computers \& Operations Research, 39(8), 1872-1878.

[4] Kahneman, D., \& Tversky, A. (1979). Prospect theory: An analysis of decision under risk. Econometrica, 47(2), 263-292.

[5] Huang, Z., \& Li. S. X. (2001). Co-op advertising models in manufacturer-retailer supply chains: A game theory approach. European Journal of Operational Research, 135(3), 527-544.

[6] Li, S. X., \& Huang, Z. (2002). Cooperative advertising, game theory and manufacturer - retailer supply chains. Omega-International Journal of Management Science, 30(3), 347-357.

[7] Xie, J., \& Ai, S. (2006). A note on "Cooperative advertising, game theory and manufacturer-retailer supply chains". Omega, 34(5), 501-504.

[8] Chen, T. (2011). Coordinating the ordering and advertising policies for a single-period commodity in a two-level supply chain. Computers \& Industrial Engineering, 61(4), 1268-1274.

[9] Maurice, E. S. G. P. C. (2000). Decision bias in the newsvendor problem with a known demand distribution experimental evidence. Management Science, 46(3), 404-420.

[10] Wang, C., \& Webster, S. (2009). The loss averse newsvendor problem. Omega, 37(1), 93-105.

[11] Lee, C., Li, X., \& Yu, M. (2015). The loss averse newsvendor problem with supply options. Naval Research Logistics (NRL), 62(1), 46-59.

[12] Luo, J., \& Chen, X. (2015). Coordination of a random yield supply chain with a loss averse supplier. Mathematical Problems in Engineering, 1-11.

[13] Charles, X., \& Wang, S. W. (2007). Channel coordination for a supply chain with a risk neutral manufacturer and a loss averse retailer. Decision sciences, 38(3), 361-389.

[14] Esmaeili, M., \& Zeephongsekul, P. (2010). Seller-buyer models of supply chain management with an asymmetric information structure. International Journal of Production Economics, 123(1), 146-154.

[15] Bergen, M., \& John, G. (1997). Understanding cooperative advertising participation rates in conventional channels. Journal of Marketing Research, 34(3), 357-369.

[16] Li, K., Mallik, S., \& Chhajed, D. (2012). Design of extended warranties in supply chains under additive demand. Production and Operations Management, 21(4), 730-746.

[17] Li, S., \& Hua, Z. (2008). A note on channel performance under consignment contract with revenue sharing. European Journal of Operational Research, 184(2), 793-796.

[18] Güler, M. G., Bilgiç, T., \& Güllü, R. (2015). Joint pricing and inventory control for additive demand models with reference effects. Annals of Operations Research, 226(1), 255-276.

[19] Xie, J., \& Neyret, A. (2009). Co-op advertising and pricing models in manufacturer-retailer supply chains. Computers \& Industrial Engineering, 56(4), 1375-1385.

[20] Xie, J., \& Wei, J. C. (2009). Coordinating advertising and pricing in a manufacturer-retailer channel. European Journal of Operational Research, 197(2), 785-791. 
[21] Yan, R. (2010). Cooperative advertising, pricing strategy and firm performance in the e-marketing age. Journal of the academy of marketing science, 38(4), 510-519.

[22] Seyed, M. M., Biazaran, M., \& Gharakhani, M. (2011). A game theoretic approach to coordinate pricing and vertical co-op advertising in manufacturer-retailer supply chains. European Journal of Operational Research, 211(2), 263-273.

[23] Zhang, J., \& Xie, J. (2012). A game theoretical study of cooperative advertising with multiple retailers in a distribution channel. Journal of Systems Science and Systems Engineering, 21(1), 37-55.

[24] Karray, S. (2013). Periodicity of pricing and marketing efforts in a distribution channel. European Journal of Operational Research, 228(3), 635-647.

[25] Ahmadi-Javid, A., \& Hoseinpour, P. (2012). On a cooperative advertising model for a supply chain with one manufacturer and one retailer. European Journal of Operational Research, 219(2), 458-466.

[26] Yue, J., Austin, J., Huang, Z., \& Chen, B. (2013). Pricing and advertisement in a manufacturer-retailer supply chain. European Journal of Operational Research, 231(2), 492-502.

[27] Berger, P. D. (1972). Vertical cooperative advertising ventures. Journal of Marketing Research, 9(3), 309-312.

[28] Yang, J., et al. (2013). Cooperative advertising in a distribution channel with fairness concerns. European Journal of Operational Research, 227(2), 401-407.

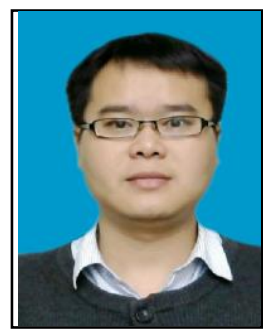

Lei Jiang is an associate professor at the Department of Mathematics, Chengdu Textile College. He obtained his master degree graduated from Sichuan University. He is the member of the China Institute of Mathematics and the visiting scholar of Tsinghua University. His research direction is in applied mathematics and management science. 